\title{
Actitudes en la interacción virtual entre los ciudadanos y los diputados del Congreso a través del correo electrónico. El caso de España 2011-2015
}

\author{
Herritarrek eta Kongresuko diputatuek elkarren \\ artean birtualki komunikatzeko dituzten jarrerak. \\ Espainiaren kasua, 2011-2015ean
}

\section{Attitudes in the virtual interaction via email between citizens and MPs. The Spanish case 2011-2015}

\section{Francisco Javier Puchades Arce ${ }^{1}$}

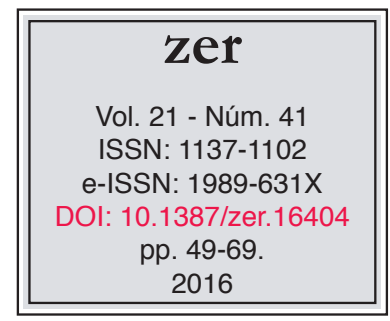

Recibido el 10 de enero de 2016, aceptado el 17 de mayo de 2016.

\section{Resumen}

La aceptación de las tecnologías de la información por parte de los políticos ha abierto nuevas vías de comunicación con la sociedad, que dispone de canales para mantener una interacción continuada. La presente es una investigación exploratoria y experimental que analiza la actitud de los diputados del Congreso en esa interacción virtual con los ciudadanos a través del email. Trata de definir, desde el punto de vista cuantitativo y cualitativo, el interés de los políticos por escuchar y entablar un diálogo permanente con la ciudadanía. Los resultados señalan las limitaciones en esa actitud, visible en un número reducido de diputados.

Palabras clave: Comunicación 2.0, interacción, ciudadanía, participación, política, redes sociales.

\section{Laburpena}

Politikariek informazio-teknologiak onartu dituzte, eta horrek bide berriak ireki dizkie gizartearekin komunikatzeko; orain, etengabe izan dezake harremana herritarrekin. Esplorazio-ikerketa esperimental honek aztertzen du Kongresuko diputatuek zein jarrera duten

${ }^{1}$ Universidad CEU - Cardenal Herrera, puarfr@alumnos.uchceu.es 
herritarrekin posta elektroniko bidez duten harreman birtual horretan. Asmoa da ikuspegi kuantitatibo eta kualitatibo batetik definitzea zein interes duten politikariek herritarrekin etengabeko elkarrizketa bat izateko. Emaitzek jarrera horretan dauden mugak adierazten dituzte, eta hori diputatu gutxi batzuetan ikus daiteke.

Gako-hitzak: 2.0 komunikazioa, interakzioa, hiritartasuna, parte-hartzea, politika, sare sozialak.

\begin{abstract}
Intense acceptance of information technologies by political representatives over the last decades has opened new communication routes between politicians and society. Citizens do have now permanent channels to maintain a continued interaction. This is an exploratory and experimental research. The article is aimed at analyzing MPs' attitude when interacting with citizens via email. It intends to define, by applying a quantitative and qualitative methodology, if it does exist any interest in politicians to listen to and set a permanent dialogue with citizens. Results indicate fair limitations in that attitude, visible in a small number of representatives within the Spanish Parliament.
\end{abstract}

Keywords: Communications 2.0, interaction, citizenship, participation, politics, social networks. 


\section{Introducción}

La irrupción de internet en la vida política y parlamentaria ha ido acompañada desde sus inicios de un intenso debate acerca de las consecuencias que las tecnologías de la información tendrían sobre la calidad del sistema democrático. Negroponte (1995: 271), Rheingold (1993: 300), Grossman (1995: 147) o Norris (2003: 43) han defendido la capacidad de internet para revitalizar la democracia gracias a la participación de la ciudadanía, cada vez más y mejor informada, en la toma de decisiones públicas a través de los canales electrónicos establecidos para ello. Frente a ellos se sitúan otros autores mucho más críticos y escépticos, para quienes no existe ninguna relación directa entre el incremento de la información que internet pone al alcance de las personas y su compromiso político (Bimber, 1998: 152; Ferber, Foltz y Pugliese, 2007: 399; Papacharisi, 2009: 35; Dahlgren, 2012: 49).

Con esta reflexión como trasfondo, los partidos políticos y sus representantes en los parlamentos e instituciones públicas se han ido subiendo al vagón de las tecnologías de la información de forma gradual.

En este entorno se han desarrollado las llamadas teorías de la igualación y la normalización, acerca de la capacidad de internet, o no, para nivelar la competición entre los partidos políticos gracias a visibilidad que pueden adquirir las formaciones más pequeñas (Balcells y Cardenal, 2013: 4). Los partidarios de la primera defienden el equilibrio de poder entre los partidos grandes y pequeños, cuyas fuerzas se igualan en internet. Los menores costes de acceso, el desarrollo de acciones alejadas de los cauces convencionales y el intento de conectar con un público más joven ha llevado a las formaciones minoritarias a multiplicar su presencia en la red, un espacio que les ha permitido sortear la escasa atención que reciben por parte de los medios convencionales.

Los trabajos de Lilleker y Jackson (2008 y 2009: 21) en el marco del Parlamento Europeo revelan, aunque con matices, que las formaciones minoritarias son más propensas a explotar algunas de las aplicaciones de la web 2.0 para abrir ciberentornos más colaborativos con los ciudadanos. Aún así, los autores defienden la existencia de una postura intermedia que identifican como una especie de web 1.5, donde el control sobre el nivel y el grado de participación de los ciudadanos continúa en manos de los partidos políticos a pesar de las posibilidades que ofrece la arquitectura de la participación.

En el lado contrario se sitúan aquellos autores para quienes internet no ha hecho más que normalizar, en el terreno online, los desequilibrios que ya existían fuera del entorno digital. Margolis y Resnick (2000: 16) consideran que el ciberespacio refleja las mismas fuerzas políticas que dominan la vida real: aquellos que pueden pagar mejores contenidos, mejor tecnología y profesionales más cualificados son los que dominan la red.

En este sentido, más de dos décadas después de que los partidos políticos españoles diesen sus primeros pasos en internet, la literatura existente refleja una realidad muy cercana a esa web 1.5 o posición intermedia a la que se referían Lilleker y Jackson. La campaña de Obama en 2008 representa un punto de inflexión porque enseña el camino sobre cómo construir espacios colaborativos y comunidades sociales entre los partidos políticos y su electorado (Rubio, 2009: 133; Harfoush, 2010: 94). Sin embargo, y a pesar del impulso renovador que significa la campaña del candidato demócrata, las webs y perfiles de los candidatos y partidos españoles en internet adolecen 
de las características de la web 1.0 en cuanto a su escaso nivel de interacción, a pesar de haber incorporado las herramientas participativas del entorno 2.0.

Los trabajos de Dader y Campos realizados entre 1999 y 2008 revelan niveles de respuesta muy bajos (inferiores al $30 \%$ ) por parte de los representantes del Congreso de los Diputados y el Senado hacia los ciudadanos que se dirigen a ellos a través del correo electrónico (Dader, 2003: 312 y Campos, 2011: 385).

La tendencia es similar en Twitter, donde los estudios realizados arrojan niveles de interacción muy limitados en forma de conversación (intercambio pregunta-respuesta) entre los candidatos y sus seguidores en las elecciones generales españoles de 2011 (Zurutuza, 2012) y las elecciones al Parlamento Vasco de 2012 (Cebrián, Vázquez y Olabarrieta, 2013: 60). Lo mismo sucede en el entorno de las Cortes Generales, donde la presencia cada vez mayor de diputados y senadores contrasta con el bajo nivel de respuesta a las menciones recibidas (Álvarez y Rodríguez, 2014: 260).

En la red social Facebook apenas se aprecian cambios, tanto en los resultados del trabajo realizado por Túñez y Sixto (2011:19-20) en el marco del Congreso de los Diputados de España, como en la investigación de Dapena y Rúas Araújo (2011: 94) centrada en el caso de los diputados del Parlamento Gallego.

Los políticos valoran las redes sociales como elemento excelente para llegar a la ciudadanía (Intelligence Compass, 2010), pero tienen miedo de perder el control histórico que han ejercido sobre el proceso de comunicación (McMillan, 2002: 285). Las páginas web de los partidos políticos españoles continúan concebidas como un gran portal de información en el que se prima la función estética y persuasiva en detrimento de los recursos destinados a la interactividad (Dader, Cheng, Campos, Quintana, y Vizcaíno-Laorga, 2014: 132). Incluso los blogs de los candidatos, a pesar de tratarse de herramientas mucho más personalistas, se emplean como instrumentos informativo-propagandísticos vinculados al mensaje ideológico de los partidos y alejados, en consecuencia, de los espacios de reflexión y debate en los que podrían convertirse (Valera, Gamir y López, 2015: 103-104).

En este escenario puede influir la ausencia de un marco legislativo que regule la relación entre diputados y ciudadanos a través de las tecnologías de la información. Organismos como la Unión Interparlamentaria Internacional ${ }^{2}$ ofrecen recomendaciones, pero no existe ninguna base legal que obligue a los parlamentarios a atender a los ciudadanos por vías electrónicas.

La ausencia de ese marco legislativo explicaría lo que ocurre al otro lado de la cadena, donde los ciudadanos muestran un interés muy limitado por acercarse a los políticos a través de las herramientas de comunicación de internet. Según el CIS ${ }^{3}$, solo un 5,2\% de los encuestados había contactado o intentado contactar con algún político para expresarle sus opiniones en los últimos 12 meses. La mayoría de la población desistiría ante la inefectividad del procedimiento, lo que convertiría los emails dirigidos a los parlamentarios en una fuente de información poco sistemática como elemento fundamental para estudiar la relación interactiva entre ciudadanos y diputados. De ahí que la presente sea una investigación exploratoria que mide actitudes, tal como se señala en el título.

2 Directrices para sitios web parlamentarios. Recuperado de http://ipu.org/PDF/publications/web-s.pdf

3 Barómetro abril 2014. Estudio 3021. Recuperado de http://www.cis.es/cis/export/sites/default/-Archivos/Marginales/3020_3039/3021/es3021mar.pdf 


\section{Objetivos y metodología}

La literatura recogida en el punto anterior refleja un escenario digital ampliamente colonizado por parte de los partidos y los políticos desde el punto de vista cuantitativo. La presente investigación parte del reconocimiento de ese escenario para adentrarse en su vertiente cualitativa. El objetivo del trabajo es analizar la relación entre los ciudadanos y los representantes políticos a través del correo electrónico. Se trata de averiguar si existe lo que Fagés Ramió (2008: 22) define como actitud 2.0, es decir observar, en ausencia de un marco legislativo que regule esa relación, la actitud de los representantes políticos a la hora interactuar con los ciudadanos a través del correo electrónico: su interés por escuchar y hablar con la ciudadanía, por compartir sus opiniones y entablar un diálogo con ella. Esa actitud se estudia a través de las modalidades de respuesta a las interacciones ciudadanas por medio del email.

Este objetivo se traduce en las siguientes preguntas de investigación: ¿están empleando los políticos las herramientas de la comunicación de internet para mantener una relación directa e interactiva con la ciudadanía? ¿Qué sucede si un ciudadano se dirige a un político a través del correo electrónico? ¿Responden los políticos? Y, si lo hacen, ¿qué clase de respuesta ofrecen? ¿Cuál es el nivel de actitud 2.0?

Para responder a estas preguntas el foco investigador se ha colocado sobre los diputados del Congreso de los Diputados en la X legislatura (2011-2015).

El correo electrónico se revela como la herramienta adecuada para realizar este análisis porque permite mantener una relación conversacional cuasi plena y muy cercana a las cualidades del discurso oral. Asimismo, los papeles de emisor y receptor son altamente intercambiables, el control sobre el contenido del mensaje reside en ambos actores y la dirección de la comunicación circula en ambas direcciones (Vela Delfa, 2005: 730; Yus Ramos, 2010: 728).

Esta dimensión conversacional, fundamental para el análisis cualitativo, no se encuentra en la red social Twitter. La extensión de 140 caracteres se convierte en una limitación narrativa que reduce la interacción al par básico de pregunta-respuesta (Izquierdo, 2012: 152; Trejo, 2011: 66; Mancera y Pano, 2013: 236).

En segundo lugar, el email goza de una amplia penetración social. Sigue siendo, tras las aplicaciones de mensajería instantánea, el servicio más utilizado por los internautas: el 70,9\% de los internautas lo ha empleado en el último mes ${ }^{4}$.

\section{Diseño de la investigación}

Para cumplir con los objetivos especificados se ha planteado una investigación que combina técnicas cuantitativas y cualitativas. En el experimento diseñado, un grupo de ciudadanos se ha dirigido periódicamente a través del correo electrónico a los diputados integrantes del Congreso de los Diputados en la X legislatura (2011-2015) que hacían pública una cuenta de email. Las respuestas recibidas se han analizado desde el punto de vista cuantitativo (índice de respuestas por grupo parlamentario) y cualitativo (análisis de contenido categorial).

\footnotetext{
${ }_{4}^{4}$ Audiencia de Internet. Abril/Mayo 2016. Recuperado de http://www.aimc.es/-Audiencia-de-Interneten-el-EGM-.html
} 
Dentro de los 3 canales de interacción entre los ciudadanos y los diputados (comunicación dirigida al partido, al grupo parlamentario o al diputado de forma directa y personal), el diseño de la investigación se ha centrado en esta última modalidad de interacción virtual personalizada.

La metodología se ha completado, en su vertiente cualitativa, con una serie de 10 entrevistas en profundidad a diputados del Congreso de los Diputados en activo durante la X legislatura. Las entrevistas se han transcrito y, posteriormente, se ha aplicado un análisis de contenido sobre las respuestas que ha permitido conocer las motivaciones, preferencias y actitudes expresadas por los diputados en cuanto al objeto de estudio ${ }^{5}$.

\subsection{La construcción de la muestra}

El universo de la investigación está formado por los 350 diputados que forman parte de la Cámara Baja. Dentro de este universo, la muestra la componen aquellos parlamentarios que publican o facilitan una cuenta de email a través de las 4 fuentes oficiales que se han consultado para su construcción.

1. Fuente A: La ficha personal de cada diputado alojada en el sitio web del Congreso de los Diputados (www.congreso.es).

2. Fuente B: Si los diputados no hacen pública una cuenta de email a través de la fuente A se ha procedido a buscar su dirección de correo electrónico en el sitio web de su partido político o grupo parlamentario a nivel nacional.

3. Fuente C: Para aquellos diputados que no hacen pública una cuenta de correo electrónico a través de las fuentes A y B, se ha procedido a buscar su email en el sitio web de la región o circunscripción del partido por el que han sido elegidos diputados. Se trata, en todos los casos, de fuentes públicas, oficiales, accesibles a todos los ciudadanos, y en las que se identifica al integrante de la muestra en su condición de diputado.

4. Fuente D: La fuente D está formada por aquellos diputados que no hacen pública una cuenta de email a través de las fuentes anteriores (A, B y C), pero sí un perfil en las redes sociales Facebook y Twitter. Esta fuente se ha añadido al diseño de la investigación con el objetivo de obtener una muestra lo más amplia y representativa posible, y asumiendo la posible preferencia de los diputados de optar por otras herramientas de comunicación 2.0 en su relación con los ciudadanos (Álvarez y Rodríguez, 2014: 272; Andueza y del Cerro, 2015: 178). A este grupo de diputados

\footnotetext{
${ }^{5}$ Las entrevistas se han efectuado en Madrid, en la sede del Congreso de los Diputados, previa concertación con los departamentos de prensa o los asistentes de los diputados, entre el 22 y el 24 de octubre de 2013. La selección de los entrevistados responde a un muestreo no probabilístico de conveniencia, en función de la disponibilidad de las agendas de los grupos parlamentarios. No obstante, se ha primado la condición de contar con representantes de todos los grupos parlamentarios. Así, la muestra de 10 diputados incluye: 2 diputados del PP, 2 del PSOE, 1 de CiU, 1 de la Izquierda Plural, 1 de UPyD, 1 del PNV y 2 representantes del grupo mixto.
} 
se les ha contactado a través de sus perfiles públicos en Facebook y Twitter para solicitarles una cuenta de correo electrónico. A los que han respondido y han facilitado una dirección de email se les ha incorporado a la muestra y se les ha enviado un correo electrónico por parte del mismo ciudadano. A los que no han respondido al mensaje de Facebook o Twitter se les ha dejado fuera de la muestra hasta la siguiente revisión y actualización de las fuentes para la composición de la muestra.

\subsection{La ejecución del trabajo de campo en 3 oleadas temporales}

En el trabajo de campo se diseñaron tres oleadas de envíos de mensajes a través del correo electrónico durante los años 2013 y 2014.

- $\quad 1^{\text {a }}$ etapa: Emails enviados entre el 1 marzo 2013 y el 30 junio 2013.

- $\quad 2^{a}$ etapa: Emails enviados entre el 1 marzo 2014 y el 30 junio 2014.

- $\quad 3^{\text {a }}$ etapa: Emails enviados entre el 1 septiembre 2014 y el 15 diciembre 2014.

Las fuentes empleadas para construir la muestra se consultaron antes, durante y después de cada una de las tres oleadas para mantenerla actualizada y certificar las posibles modificaciones acaecidas a causa de las altas y bajas de diputados.

El cuadro 1 representa, de forma gráfica, el proceso de composición de la muestra adaptada al trabajo de campo en tres oleadas. Tal como se indica, la muestra es la suma de las direcciones de email obtenidas a través de las cuatro fuentes consultadas. No obstante, y aunque las fuentes se revisaron antes, durante y después de cada oleada para actualizar la muestra, las cuentas de correo obtenidas por medio de la fuente D se acumularon en las sucesivas oleadas. En otras palabras, no volvió a solicitar a través de Facebook o Twitter una cuenta de email a aquellos parlamentarios que ya la habían facilitado en la primera o segunda oleada. En este caso, su cuenta se incorporó a la muestra de forma definitiva para las sucesivas oleadas.

Cuadro 1. Selección de la muestra.

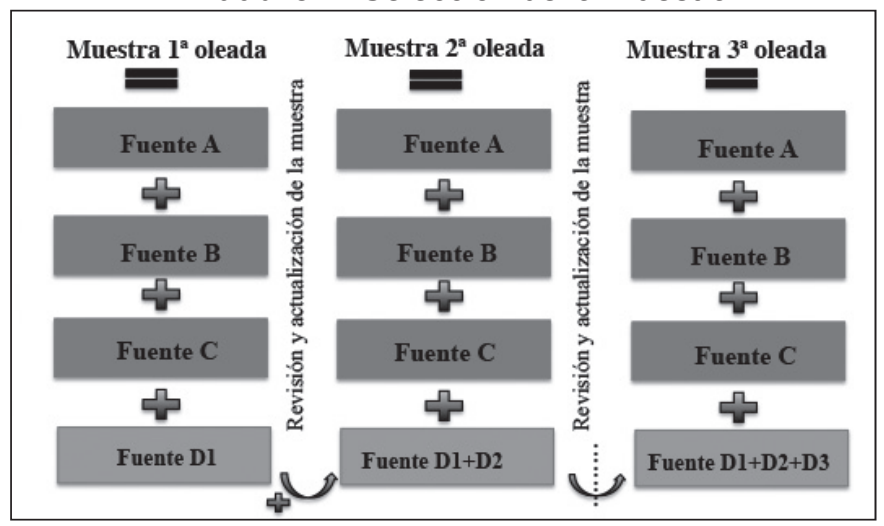

Fuente: Elaboración propia. 


\subsection{La creación y gestión del grupo de ciudadanos}

Para ejecutar los envíos a lo largo de cada una de las tres oleadas se creó un grupo de 30 ciudadanos reales que aceptaron participar en la investigación. Cada uno de ellos creó una cuenta de correo electrónico a través de la cual se realizaron los envíos a cada uno de los diputados integrantes de la muestra. El procedimiento para la selección y creación del grupo de ciudadanos responde a un muestreo no probabilístico de conveniencia, ya que se trata de individuos pertenecientes al entorno social del investigador.

De la misma forma, 5 de los 30 ciudadanos crearon un perfil en las redes sociales Facebook y Twitter con el objetivo de contactar a través de estos espacios con aquellos diputados que no hacían pública una cuenta de email, pero sí un perfil a través de estas dos redes sociales.

\subsection{El contenido de los mensajes}

El contenido del mensaje de cada uno de los correos electrónicos se personalizó para adaptarlo a cada uno de los diputados receptores. Asimismo, para garantizar la pertinencia de los mensajes, a cada parlamentario se le interpeló acerca de materias que son competencia de la comisión o comisiones parlamentarias a las que pertenece. La personalización del mensaje se reforzó en el encabezamiento (con el nombre y apellidos del diputado receptor) y en el cierre (con el nombre y apellidos del ciudadano remitente, un agradecimiento y una fórmula de cortesía para despedir).

Todos los correos se redactaron en un estilo formal y neutro, alejado de cualquier rasgo que denotara simpatía o filiación política alguna. De la misma forma, todos disponían de una extensión similar en cuanto al número de líneas y de una estructura en tres partes: introducción (el ciudadano identifica al diputado receptor por su nombre y apellidos), cuerpo del mensaje (el ciudadano plantea la cuestión y formula una pregunta concreta al diputado) y cierre (el ciudadano agradece la atención y se despide con una fórmula de cortesía).

Sobre la base de las tres oleadas de envíos temporales se diseñaron dos clases de mensajes diferentes para analizar la respuesta de los diputados ante cada uno de los escenarios. Para la primera y segunda oleada se elaboraron Mensajes-Desarrollo (MD). Poseían entre 13 y 18 líneas de extensión e interpelaban al diputado acerca de cuestiones relacionadas con su área de competencia dentro de la cámara. Los MD requerían un mínimo de tiempo y dedicación para ser leídos, comprendidos y respondidos. El ciudadano demuestra un certero nivel de conocimiento acerca de la materia sobre la que interpela, y puede que el diputado, en el caso de responder, necesite consultar documentación o recurrir a algún asesor. El siguiente ejemplo corresponde a un email enviado por un ciudadano a un diputado integrante de la Comisión de Asuntos Exteriores:

Asunto: Ayudas a las víctimas de minas antipersona en la nueva Ley de prohibición

Estimado... (nombre y apellidos del diputado receptor) 
La ley de prohibición de minas antipersona continua su tramitación después de haber superado el primer trámite parlamentario. La comisión competente, según he leído, es la Comisión de Asuntos Exteriores de la que usted forma parte. Por eso me pongo en contacto con usted, porque tengo algunas breves dudas que me gustaría plantearle de forma muy concreta. Según tengo entendido, a través de esta ley el Gobierno se compromete a destruir todas las minas antipersona o municiones de racimo, incluso aquellas que puedan haber sido descubiertas con posterioridad a la entrada en vigor de los tratados y leyes internacionales. Sin embargo, ¿qué dice la ley acerca de la ayuda y asistencia a las personas víctimas de minas antipersona y restos explosivos de material de guerra? ¿qué dice la ley acerca de atención médica, psicológica, prevención, ayuda psicológica para las víctimas? ¿Se va a seguir prestando esta ayuda?

\section{Le agradezco su atención}

Un cordial saludo (nombre y apellidos del ciudadano remitente)

En la tercera oleada, el contenido de los Mensajes-Desarrollo (MD) se sustituyó por Mensajes-Función (MF). Estos mantenían el mismo estilo de redacción y estructura en tres partes, pero el contenido del mensaje era mucho más escueto: entre 3 y 6 líneas. Se interpelaba a los diputados acerca de cuestiones relacionadas con su área de competencia dentro de la cámara, pero el contenido del mensaje era mucho más rápido y sencillo de leer y responder por parte del diputado. Se trataba, en todos los casos, de cuestiones relacionadas con el funcionamiento ordinario de las comisiones a las que pertenece el diputado (cómo se puede acceder al orden del día, cómo se puede descargar el diario de sesiones, qué opciones hay para seguir los plenos vía online etc.). El siguiente ejemplo corresponde a la interpelación a un diputado de la Comisión de Economía:

Asunto: Consulta de los diarios de sesiones de la Comisión de Economía

Diputado (nombre y apellidos del diputado receptor), buenos días.

Quiero consultar los diarios de sesiones de la última reunión de la Comisión de Economía, de la que usted forma parte, sin tener que desplazarme físicamente a Madrid. ¿Están disponibles y se pueden consultar a través de internet en la web del Congreso?

Gracias por su atención. Un saludo.

(Nombre y apellidos del ciudadano remitente)

Todos los mensajes se redactaron de forma específica e individualizada para cada una de las oleadas. Tal como se ha explicado anteriormente, tanto los MD como los MF introducían una cuestión concreta en el cuerpo del mensaje. El ciudadano planteaba una pregunta al diputado, reforzada con el empleo de los signos de inte- 
rrogación, porque esperaba de él una respuesta recíproca en forma de interacción. Este elemento es importante porque una de las categorías empleadas en el análisis de contenido de las respuestas tiene en cuenta si el diputado responde y resuelve la cuestión formulada por su interlocutor.

En el caso de los mensajes enviados a través de Facebook y Twitter, el contenido del mensaje se adaptó al objetivo planteado (solicitar una cuenta de email al diputado receptor) y a las especificidades del canal en cada uno de los casos. En el caso de Twitter, la limitación del contenido a 140 caracteres condicionó la redacción (ej."Estimado diputado, su dirección de email no figura en la web del Congreso. ¿A qué dirección podría escribirle? Gracias"), mientras que en Facebook se elaboraron textos más extensos al no existir limitaciones de espacio. Un ejemplo de los mensajes remitidos a través de Facebook es el siguiente:

Estimado diputado (nombre y apellidos del diputado receptor)

Buenas tardes. Me gustaría plantearle una serie de cuestiones a través del correo electrónico en su calidad de diputado del GPP en el Congreso. ¿Podría facilitarme una dirección de email oficial? No he encontrado ninguna dirección de email en la web del Congreso ni tampoco en la de su partido. Sí aparecía este enlace de Facebook, y por eso le he escrito aquí.

Muchas gracias,

Un saludo

(Nombre y apellidos del ciudadano remitente)

A diferencia de la ejecución empleada a través del email, los mensajes remitidos a través de Facebook y Twitter poseían las mismas características a lo largo de las tres oleadas. Se varió su redacción a través de diversas fórmulas, pero la extensión, estilo y la interpelación que contenían (solicitar al diputado una cuenta de correo electrónico) se mantuvieron invariables. Para aquellos parlamentarios que a través de las fuentes A, B o C hacían públicos perfiles en ambas redes sociales se optó por contactarles a través de Facebook. Se procedió de esa manera porque esta red social permite el envío de mensajes privados (sin necesidad de que los usuarios se sigan mutuamente) y porque no exige limitación de caracteres en la redacción. En Twitter, el ciudadano remitente iniciaba una conversación en el muro o espacio público del perfil del diputado. Todos los perfiles de Facebook y Twitter son públicos y oficiales (obtenidos a través de las fuentes A, B y C) y en ellos se identifica al representante público en su condición de diputado.

\subsection{El análisis de contenido categorial}

Para desarrollar el análisis cualitativo planteado en el diseño de la investigación se aplicó un análisis de contenido categorial a partir de las categorías e indicadores de- 
finidos en el cuadro número 2. Estas categorías e indicadores se aplicaron a cada una de las unidades de análisis o muestreo, correspondientes a cada uno de los emails de respuesta de los diputados.

Cuadro 2. Análisis de contenido categorial: categorías e indicadores.

\begin{tabular}{|c|c|c|}
\hline Categoría & Indicador & Descripción \\
\hline \multirow{2}{*}{ RESPUESTA } & Respuesta & Contesta al envío \\
\hline & No respuesta & No contesta al envío \\
\hline \multirow{2}{*}{ ACCIÓN } & $\begin{array}{c}\text { Respuesta } \\
\text { delegada }\end{array}$ & $\begin{array}{l}\text { Responde un asistente del equipo o grupo } \\
\text { del diputado }\end{array}$ \\
\hline & $\begin{array}{l}\text { Respuesta } \\
\text { personalizada }\end{array}$ & El diputado responde personalmente \\
\hline \multirow{3}{*}{ CONTENIDO } & Respuesta sucinta & $\begin{array}{l}\text { El diputado responde, pero no resuelve la } \\
\text { cuestión que le formula su interlocutor }\end{array}$ \\
\hline & $\begin{array}{l}\text { Respuesta } \\
\text { disociada }\end{array}$ & $\begin{array}{l}\text { El diputado no resuelve la cuestión } \\
\text { planteada. Su respuesta no tiene nada que } \\
\text { ver con el tema planteado por su interlocutor }\end{array}$ \\
\hline & $\begin{array}{l}\text { Respuesta } \\
\text { argumentada }\end{array}$ & $\begin{array}{l}\text { El diputado responde y resuelve la cuestión } \\
\text { planteada por su interlocutor }\end{array}$ \\
\hline \multirow{2}{*}{$\begin{array}{l}\text { COMUNICACIÓN } \\
\text { DE TIPO POLÍTICO- } \\
\text { PROPAGANDÍSTICO }\end{array}$} & $\begin{array}{l}\text { Respuesta } \\
\text { politizada }\end{array}$ & $\begin{array}{l}\text { El diputado aprovecha la respuesta para } \\
\text { defender la posición política de su partido en } \\
\text { un asunto determinado y/o criticar la de otro } \\
\text { partido rival. }\end{array}$ \\
\hline & Respuesta técnica & $\begin{array}{l}\text { El diputado responde con datos técnicos y } \\
\text { no entra en consideraciones políticas }\end{array}$ \\
\hline \multirow{2}{*}{ TIEMPO } & $\begin{array}{l}\text { Respuesta } \\
\text { inmediata }\end{array}$ & $\begin{array}{l}\text { El diputado contesta dentro de los tres días } \\
\text { posteriores al envío inicial del correo }\end{array}$ \\
\hline & $\begin{array}{l}\text { Respuesta } \\
\text { demorada }\end{array}$ & $\begin{array}{l}\text { El diputado contesta a partir del cuarto día } \\
\text { tras el envío inicial del correo }\end{array}$ \\
\hline
\end{tabular}

Fuente: Elaboración propia.

\section{Análisis de resultados}

El análisis de resultados se divide en dos subapartados. En el primero se analiza la disponibilidad de los diputados del Congreso para publicar o facilitar una cuenta de email a través de las fuentes A, B, C y D empleadas para componer la muestra. El segundo subapartado consiste en el análisis de los índices de respuesta obtenidos en cada una de las tres oleadas del trabajo de campo, así como el análisis de contenido categorial de los mensajes de respuesta. Este análisis es el que conducirá a la validación o refutación de las hipótesis planteadas.

\subsection{Análisis de la disponibilidad de los diputados del Congreso de los Diputados para publicar o facilitar una cuenta de correo electrónico}

Según lo especificado en el punto 3.1, la muestra de la investigación está formada por aquellos diputados que publican o facilitan una cuenta de email a través de las 4 
fuentes de información que se han consultado para su construcción. Entre estas fuentes, figuran los perfiles de Facebook y Twitter (fuente D) de aquellos diputados que no hacen pública una cuenta de email pero sí un perfil a través de estas redes sociales. Los integrantes del grupo de ciudadanos se dirigieron a los diputados por medio de esta vía para solicitarles una cuenta de email. Sobre este punto, el cuadro 3 indica la relación entre los diputados contactados a través de Facebook/Twitter y aquellos que respondieron favorablemente al ciudadano para facilitarle una dirección de correo electrónico ${ }^{6}$.

Cuadro 3. Diputados que facilitan una cuenta de email a través de Facebook o Twitter (fuente D).

$1^{\text {a }}$ oleada

\begin{tabular}{|c|c|c|}
\hline & $\begin{array}{c}\text { Diputados con cuenta } \\
\text { de Facebook o Twitter }\end{array}$ & $\begin{array}{c}\text { Diputados que responden y } \\
\text { facilitan una cuenta de @ a } \\
\text { través de Facebook o Twitter }\end{array}$ \\
\hline Grupo Parlamentario PP & 16 & 0 \\
\hline Grupo Parlamentario PSOE & 6 & - \\
\hline Grupo Parlamentario CiU & - & 0 \\
\hline $\begin{array}{c}\text { Grupo Parlamentario La } \\
\text { Izquierda Plural }\end{array}$ & 1 & 3 \\
\hline Grupo Parlamentario UPyD & 5 & 1 \\
\hline $\begin{array}{c}\text { Grupo Parlamentario } \\
\text { EAJ-PNV }\end{array}$ & 3 & $\mathbf{6 ~ ( 1 7 , 1 \% )}$ \\
\hline Grupo Parlamentario Mixto & 4 & \\
\hline TOTAL & $\mathbf{3 5}$ & \multicolumn{2}{c|}{} \\
\hline
\end{tabular}

$2^{a}$ oleada

\begin{tabular}{|c|c|c|}
\hline & $\begin{array}{c}\text { Diputados con cuenta } \\
\text { de Facebook o Twitter }\end{array}$ & $\begin{array}{c}\text { Diputados que responden y } \\
\text { facilitan una cuenta de @ a } \\
\text { través de Facebook o Twitter }\end{array}$ \\
\hline Grupo Parlamentario PP & 31 & 1 \\
\hline Grupo Parlamentario PSOE & 4 & 1 \\
\hline Grupo Parlamentario CiU & - & 0 \\
\hline $\begin{array}{c}\text { Grupo Parlamentario La } \\
\text { Izquierda Plural }\end{array}$ & 2 & 1 \\
\hline Grupo Parlamentario UPyD & 2 & 0 \\
\hline $\begin{array}{c}\text { Grupo Parlamentario } \\
\text { EAJ-PNV }\end{array}$ & 1 & 3 \\
\hline Grupo Parlamentario Mixto & 3 & $\mathbf{6 ~ ( 1 4 \% )}$ \\
\hline TOTAL & $\mathbf{4 3}$ & \\
\hline
\end{tabular}

6 Todos los integrantes del grupo parlamentario catalán (CiU) publican una cuenta de email a través de las fuentes A, B ó C. Por ese motivo no ha sido necesario contactar con ellos a través de sus perfiles en redes sociales. Sucede lo mismo con los representantes del grupo de UPyD y grupo Mixto en la $3^{\text {a }}$ oleada. 
$3^{a}$ oleada

\begin{tabular}{|c|c|c|}
\hline & $\begin{array}{c}\text { Diputados con cuenta } \\
\text { de Facebook o Twitter }\end{array}$ & $\begin{array}{c}\text { Diputados que responden y } \\
\text { facilitan una cuenta de @ a } \\
\text { través de Facebook o Twitter }\end{array}$ \\
\hline Grupo Parlamentario PP & 23 & 0 \\
\hline Grupo Parlamentario PSOE & 2 & 0 \\
\hline Grupo Parlamentario CiU \\
$\begin{array}{c}\text { Grupo Parlamentario La } \\
\text { Izquierda Plural }\end{array}$ & - & 0 \\
\hline Grupo Parlamentario UPyD & 1 & - \\
\hline $\begin{array}{c}\text { Grupo Parlamentario } \\
\text { EAJ-PNV }\end{array}$ & - & 0 \\
\hline Grupo Parlamentario Mixto & 2 & - \\
\hline TOTAL & - & $\mathbf{0}$ \\
\hline
\end{tabular}

Fuente: Elaboración propia.

En análisis de los datos del cuadro 3 revela que, de los 106 diputados contactados a lo largo de las tres oleadas por medio de las redes sociales Facebook y Twitter, un total de $12(11,3 \%)$ respondieron favorablemente para facilitar una cuenta de email a los ciudadanos. El índice de respuesta en la primera y segunda oleada se quedó en el 17,1 y el $14 \%$, respectivamente, mientras que en la tercera oleada no se obtuvo ninguna respuesta. Según estos datos, las redes sociales Facebook y Twitter tienen un funcionamiento limitado como canal de comunicación efectivo entre los ciudadanos y los diputados del Congreso, a pesar de la preferencia de los representantes públicos por este tipo de herramientas en su relación con los ciudadanos (Álvarez y Rodríguez, 2014: 272; Andueza y del Cerro, 2015: 178).

Según la metodología diseñada (ver cuadro 1), la cuentas de correo electrónico obtenidas a través de la interacción en redes sociales se incorporaron a la muestra de la investigación a lo largo de cada una de las tres oleadas del trabajo de campo. De esta manera, la composición de la muestra con la que se trabajó durante la investigación (direcciones obtenidas a través de las fuentes A, B, C y D) aparece recogida en el cuadro número 4.

El análisis de los datos del cuadro 4 indica que más de 3/4 partes de los diputados del Congreso hacía pública o facilitaba una dirección de email a través de la cual contactar con ellos. El porcentaje de disponibilidad oscila entre el 76 y el $79 \%$ de sus integrantes. Eso significa que, a lo largo de las tres oleadas, al menos 7 de cada 10 diputados de la Cámara Baja fueron accesibles a través del correo electrónico, bien porque lo publicaban en su ficha personal del sitio web del Congreso o de su partido, bien porque lo facilitaron a través de las redes sociales a los ciudadanos que se lo habían solicitado. 
Cuadro 4. Diputados que publican o facilita una dirección de email a través de las fuentes $A, B, C$ y D. Composición de la muestra.

\section{$1^{a}$ oleada}

\begin{tabular}{|c|c|c|}
\hline & Con @ & Sin @ \\
\hline Grupo Parlamentario PP & 127 & 58 \\
\hline Grupo Parlamentario PSOE & 96 & 14 \\
\hline Grupo Parlamentario CiU & 16 & 0 \\
\hline $\begin{array}{c}\text { Grupo Parlamentario La } \\
\text { Izquierda Plural }\end{array}$ & 9 & 2 \\
\hline $\begin{array}{c}\text { Grupo Parlamentario UPyD } \\
\text { Grupo Parlamentario } \\
\text { EAJ-PNV }\end{array}$ & 3 & 2 \\
\hline Grupo Parlamentario Mixto & 3 & 5 \\
\hline TOTAL & $\mathbf{2 6 7}\left(\mathbf{7 6} \mathbf{6}^{\prime} \mathbf{3} \%\right)$ & $\mathbf{8 3} \mathbf{( 2 3 ^ { \prime } \mathbf { 7 } ^ { \prime } \% )}$ \\
\hline
\end{tabular}

\begin{tabular}{|c|c|c|}
\hline \multicolumn{3}{|c|}{$2^{a}$ oleada } \\
\hline & Con@ & Sin @ \\
\hline Grupo Parlamentario PP & 120 & 65 \\
\hline Grupo Parlamentario PSOE & 100 & 10 \\
\hline Grupo Parlamentario CiU & 15 & 1 \\
\hline $\begin{array}{c}\text { Grupo Parlamentario La } \\
\text { Izquierda Plural }\end{array}$ & 9 & 2 \\
\hline Grupo Parlamentario UPyD & 4 & 1 \\
\hline $\begin{array}{c}\text { Grupo Parlamentario } \\
\text { EAJ-PNV }\end{array}$ & 3 & 2 \\
\hline Grupo Parlamentario Mixto & 18 & 0 \\
\hline TOTAL & $269(76 ’ 9 \%)$ & $81(23,1 \%)$ \\
\hline
\end{tabular}

\begin{tabular}{|c|c|c|}
\hline \multicolumn{3}{|c|}{$3^{a}$ oleada } \\
\hline & Con@ & Sin @ \\
\hline Grupo Parlamentario PP & 125 & 60 \\
\hline Grupo Parlamentario PSOE & 102 & 8 \\
\hline Grupo Parlamentario CiU & 16 & 0 \\
\hline $\begin{array}{c}\text { Grupo Parlamentario La } \\
\text { Izquierda Plural }\end{array}$ & 10 & 1 \\
\hline Grupo Parlamentario UPyD & 5 & 0 \\
\hline $\begin{array}{c}\text { Grupo Parlamentario } \\
\text { EAJ-PNV }\end{array}$ & 3 & 2 \\
\hline Grupo Parlamentario Mixto & 18 & 0 \\
\hline TOTAL & $279(79 ’ 7 \%)$ & $71\left(20{ }^{\prime} 3 \%\right)$ \\
\hline
\end{tabular}

Fuente: Elaboración propia. 


\subsection{Discusión de los resultados}

Los resultados del análisis cuantitativo aparecen recogidos en el cuadro número 5. Este análisis revela índices de respuesta que, en ninguno de los 3 escenarios analizados, superaron el $50 \%$ de los integrantes de la muestra, situándose muy por debajo de ese registro tanto en la primera como en la segunda oleada ( 22 y $18,6 \%$, respectivamente). Eso significa que el porcentaje de diputados que muestran una actitud comunicativa proclive a interactuar con la ciudadanía a través del email fue, en el mejor de los escenarios observados, del 48,7\%, es decir por debajo del $50 \%$ de la muestra.

El índice de respuesta más elevado se obtuvo coincidiendo con el envío de los MF. Este porcentaje duplicó los registros de las dos oleadas anteriores. El análisis de estos resultados indica que los diputados respondieron más cuando el contenido de los mensajes remitidos por los ciudadanos se podía leer y resolver de forma rápida y sencilla, es decir ante cuestiones que requieren esfuerzo limitado para aportar la información solicitada por el interlocutor.

Cuadro 5. Resultados e índices de respuesta.

\begin{tabular}{|c|c|c|}
\multicolumn{4}{|c|}{$1^{\text {a oleada }}$} \\
\hline Grupo Parlamentario PP & Con @ & Responden \\
\hline Grupo Parlamentario PSOE & 127 & $34(11 \%)$ \\
\hline Grupo Parlamentario CiU & $96 \%)$ \\
\hline $\begin{array}{c}\text { Grupo Parlamentario La } \\
\text { Izquierda Plural }\end{array}$ & 16 & $5\left(31{ }^{\prime} \% \%\right)$ \\
\hline Grupo Parlamentario UPyD & 9 & $2(11 \%)$ \\
\hline $\begin{array}{c}\text { Grupo Parlamentario } \\
\text { EAJ-PNV }\end{array}$ & 3 & 0 \\
\hline Grupo Parlamentario Mixto & 13 & $3(23 \%)$ \\
\hline TOTAL & $\mathbf{2 6 7}$ & $\mathbf{5 9}(\mathbf{2 2} \%)$ \\
\hline
\end{tabular}

$2^{a}$ oleada

\begin{tabular}{|c|c|c|}
\hline & Con @ & Responden \\
\hline Grupo Parlamentario PP & 120 & $19\left(15^{\prime} 9 \%\right)$ \\
\hline Grupo Parlamentario PSOE & 100 & $25(25 \%)$ \\
\hline Grupo Parlamentario CiU & 15 & $2\left(13^{\prime} 3 \%\right)$ \\
\hline $\begin{array}{c}\text { Grupo Parlamentario La } \\
\text { Izquierda Plural }\end{array}$ & 9 & $1\left(11^{\prime} 1 \%\right)$ \\
\hline Grupo Parlamentario UPyD & 4 & $2(50 \%)$ \\
\hline $\begin{array}{c}\text { Grupo Parlamentario } \\
\text { EAJ-PNV }\end{array}$ & 3 & 0 \\
\hline Grupo Parlamentario Mixto & 18 & $1\left(5^{\prime} 5 \%\right)$ \\
\hline TOTAL & $\mathbf{2 6 9}$ & $\mathbf{5 0}\left(\mathbf{1}^{\prime} \mathbf{6} \%\right)$ \\
\hline
\end{tabular}


$3^{a}$ oleada

\begin{tabular}{|c|c|c|}
\hline & Con@ & Responden \\
\hline Grupo Parlamentario PP & 125 & $52\left(41^{\prime} 6 \%\right)$ \\
\hline Grupo Parlamentario PSOE & 102 & $62\left(600^{\prime} 7 \%\right)$ \\
\hline Grupo Parlamentario CiU & 16 & $8(50 \%)$ \\
\hline $\begin{array}{c}\text { Grupo Parlamentario La } \\
\text { Izquierda Plural }\end{array}$ & 10 & $4(40 \%)$ \\
\hline Grupo Parlamentario UPyD & 5 & $4(80 \%)$ \\
\hline $\begin{array}{c}\text { Grupo Parlamentario } \\
\text { EAJ-PNV }\end{array}$ & 3 & 0 \\
\hline Grupo Parlamentario Mixto & 18 & $6\left(333^{\prime} 3 \%\right)$ \\
\hline TOTAL & 279 & $136\left(48^{\prime} 7 \%\right)$ \\
\hline
\end{tabular}

Fuente: Elaboración propia.

Según las opiniones expresadas por los diputados en las entrevistas en profundidad, el email sigue siendo una de las principales vías de comunicación con la ciudadanía. A diario reciben consultas y sugerencias ciudadanas a través de este canal. Aseguraron que intentan responder a todos los correos, aunque reconocieron que no siempre era posible a causa de las siguientes razones: la gran cantidad de mensajes que reciben, la carga de trabajo parlamentario unido a la ausencia de ayuda para desarrollar esta tarea en forma de auxiliares o asistentes, y la desconfianza en la identidad online del remitente (envío de campañas masivas que pueden llegar a saturar la bandeja de entrada o envío de spam). En este sentido, se produciría lo que Dertouzos (1997: 126) identifica como desequilibrios asociados a la interactividad. De las respuestas de los diputados también se desprendía la eventual saturación de sus bandejas de entrada a la que aluden algunos autores como Andueza y del Cerro (2015: 178).

Tal como se observa en el análisis del cuadro 6, el cruce de los índices de respuesta con la variable "grupo parlamentario" no refleja un mejor comportamiento de los grupos minoritarios respecto a los mayoritarios. El grupo de UPyD obtuvo los mejores índices de respuesta: $66,6 \%, 50 \%$ y $80 \%$, respectivamente) a lo largo de las tres oleadas del trabajo de campo. No obstante, estos resultados no se reproducen en el resto de grupos minoritarios, cuyos registros quedaron siempre por debajo de alguno de los dos mayoritarios (PP o PSOE). Entre estos últimos, destaca el comportamiento del grupo Socialista, que obtuvo los índices de respuesta más elevados $(35,4 \%$, $25 \%$ y $60,7 \%$ ) después de UPyD. El grupo Socialista mejoró los registros del resto de formaciones minoritarias y también los de su principal rival parlamentario en el Congreso, el grupo Popular.

El análisis cualitativo revela el esfuerzo de los diputados a la hora de resolver las cuestiones planteadas por los ciudadanos en los correos electrónicos. En otras palabras, respondieron pocos pero, entre aquellos que sí lo hicieron, la calidad de la respuesta fue más que aceptable. Según la categoría contenido, la más relevante para el análisis cualitativo, la media de respuestas argumentadas a lo largo de las tres oleadas fue del $84 \%(73 \%, 80 \%$ y $99 \%$ en la primera, segunda y tercera oleada, respectivamente). 
Cuadro 6. Índice de respuesta por grupo parlamentario.

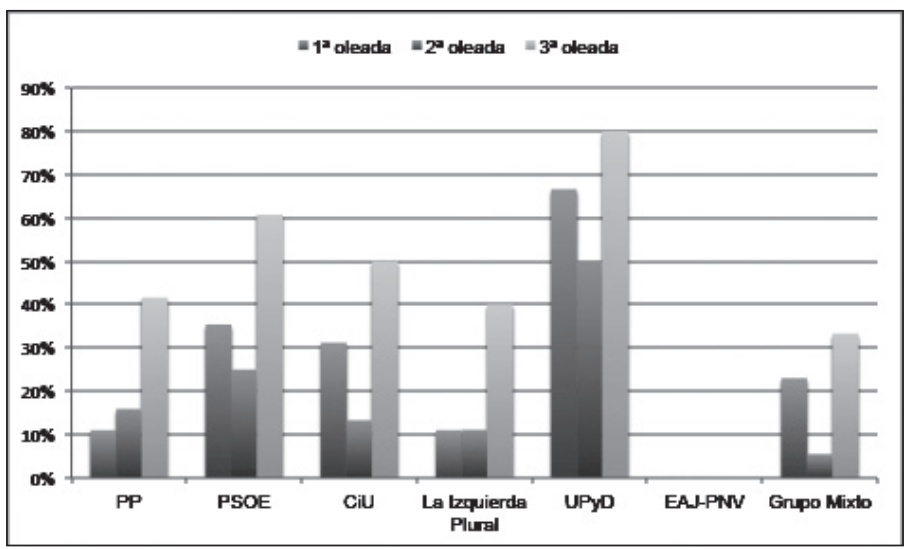

Fuente: Elaboración propia.

El análisis de contenido categorial también indica que los diputados del Congreso manejaban su cuenta de correo electrónico, en su mayoría, de forma personal e individualizada. La media de respuestas personalizadas a lo largo de las tres oleadas fue del $82,3 \%$ (86\% en la primera oleada, $84 \%$ en la segunda y $77 \%$ en la tercera, respectivamente). Sobre este punto, y según lo expresado por los diputados en las entrevistas en profundidad, sólo aquellos parlamentarios con responsabilidades de portavoz, o con mayor carga de trabajo parlamentario, disponían de un asistente parlamentario. El resto de diputados contaba con el apoyo de los técnicos o adjuntos que trabajan para el grupo parlamentario y que comparten entre todos.

Los datos relativos a la categoría tiempo revelan que los diputados del Congreso tardaron una media de 2,4 días en responder (1,8 días; 3,6 días y 1,8 días en la primera, segunda y tercera oleada, respectivamente). Kalman y Rafaeli (2005: 7) sugieren que la rapidez en esta tarea reduce el riesgo asociado a la procrastinación. Cuanto más rápido se responde más baja es la probabilidad de que los mensajes se queden sin contestar. En este sentido, una demora media de 2,4 días se considera más que aceptable, y se estima que contribuye a reforzar el nivel de calidad de las respuestas.

El análisis de contenido categorial también indica que los diputados de grupos de la oposición recurrían en mayor medida a los recursos de la comunicación de tipo político-propagandístico. 39 de las 109 respuestas $(35,7 \%)$ que se registraron entre la primera y la segunda oleada (en la tercera oleada no se analizó esta categoría por el carácter funcional de los mensajes) se consideraron politizadas. De ellas, el 92,3\% (un total de 36) provenían de diputados de grupos de la oposición. Recurrían a la comunicación de tipo político-propagandístico para criticar las políticas del partido en el Gobierno y trasladar un mensaje persuasivo en contra de las actuaciones del Ejecutivo. No obstante, y a pesar de este matiz, el análisis de resultados confirma que el $64,3 \%$ (un total de 70) de las respuestas recogidas entre la primera y la segunda oleada se consideraron técnicas, es decir el diputado responde al ciudadano con datos técnicos y no entra en consideraciones políticas. 


\section{Conclusiones}

En una etapa de desafección y desconfianza hacia la política, las herramientas de comunicación de internet que se han explorado en esta investigación se intuyen como instrumentos capaces de estrechar la relación con la sociedad y de mejorar la transparencia de las instituciones políticas. Partiendo de los objetivos planteados en el punto 2, los resultados del trabajo de campo indican que, en el mejor de los escenarios observados, el 48,7\% de los diputados del Congreso que publica o facilita una cuenta de email muestra una actitud comunicativa proclive a interactuar con la ciudadanía a través de esta vía.

Los resultados se consideran limitados si se tiene en cuenta que este registro no supera el $50 \%$ de los integrantes de la muestra y si se añade que, en la primera y segunda oleada del trabajo de campo, las cifras que miden esta actitud han sido inferiores ( $22 \%$ y $18,6 \%$, respectivamente).

Por grupos parlamentarios, las formaciones minoritarias no muestran una actitud más intensa, respecto a los grupos mayoritarios en la cámara, para interactuar con los ciudadanos que se dirigen a ellos a través de esta vía. El grupo de UPyD obtiene los mejores resultados en cada una de las tres oleadas analizadas, si bien la predisposición en la actitud de sus diputados hacia el email como herramienta de comunicación con el ciudadano no se observa en el resto de formaciones minoritarias, cuyos registros quedan siempre por debajo de alguno de los dos grupos mayoritarios (PP o PSOE).

Más allá de los datos cuantitativos, el análisis cualitativo indica que, aquellos diputados que muestran una actitud positiva hacia la interacción vía email, cumplen con unos estándares de calidad elevados en sus respuestas. La mayoría de estas respuestas llegan en tiempo y resuelven la cuestión planteada por su interlocutor.

En ausencia de un marco legislativo que regule la relación entre los representantes parlamentarios y los ciudadanos a través de los canales electrónicos, las respuestas de los diputados parecen quedar en el terreno de la cortesía protocolaria o, incluso, de la estética, es decir como recurso para ganarse una buena imagen ante el electorado.

La cuestión que se plantea es relevante, ya que a las bandejas de entrada de las cuentas oficiales de los diputados llegan cada día gran cantidad de emails con mensajes y cuestiones planteadas por la ciudadanía. Que una parte sustancial de estos mensajes se quede sin responder, o que estos sean contestados de forma discrecional, puede generar una imagen negativa en la sociedad, incidiendo en la desafección hacia la política y alimentando el malestar de los ciudadanos al sentirse desatendidos por sus representantes públicos.

Por este motivo, sería necesario plantear la generación de protocolos internos por parte de las formaciones políticas para formalizar la interacción a través de las vías electrónicas. Este protocolo interno debería ir acompañado de cierta profesionalización en forma de equipos de personas encargadas de ayudar a los diputados en la tarea de recibir, procesar y responder a los mensajes de las comunicaciones electrónicas. Estos recursos humanos se deberían destinar a atender no solo las comunicaciones dirigidas al partido y al grupo parlamentario, sino también aquellas remitidas al diputado de forma personal e individualizada. 
En la llamada democracia digital o ciberdemocracia, el desarrollo de los canales y las herramientas electrónicas ha ido mucho más deprisa que el de los recursos para gestionar el volumen de interacciones que ésta ha generado. Asumiendo los desequilibrios asociados a la interactividad que señalaba Dertouzos (1997: 126), es evidente que no se puede cargar a los parlamentarios con la responsabilidad exclusiva de gestionar su correspondencia electrónica en solitario. De ser así, se correría el riesgo de bloquear su actividad parlamentaria que, como es sabido, va mucho más allá de atender a las cuestiones remitidas por la ciudadanía. Es por ello que el protocolo interno al cual se hacía referencia debería tener en cuenta los recursos humanos y técnicos necesarios para dar respuesta a esa interactividad. En el caso del grupo parlamentario de UPyD, tanto la entrevista en profundidad como el análisis de contenido de las respuestas obtenidas, revelan la existencia de cierta coordinación interna para que, con ayuda de los técnicos parlamentarios del grupo, los diputados puedan responder a las cuestiones planteadas por los ciudadanos a través del correo electrónico.

En cuanto a las limitaciones de la investigación cabría señalar, además de la ausencia del citado marco legislativo (que convierte a los correos dirigidos a los parlamentarios en una fuente de información poco sistemática como elemento fundamental para estudiar la interacción), la posible saturación de los buzones de entrada de los parlamentarios, sometidos al bombardeo de las campañas masivas y los correos basura. Este hecho establecería claramente que nos encontremos ante una investigación exploratoria, planteada con el objetivo de medir y analizar actitudes.

\section{Referencias bibliográficas}

ÁLVAREZ, D. y RODRÍGUEZ, R. (2014). Parlamentarios 2.0: presencia y actividad de diputados y senadores españoles en las redes sociales. En R. RUBIO (coord.), Parlamentos Abiertos. Tecnología y redes para la democracia (pp. 235-276). Madrid: Congreso de los Diputados.

ANDUEZA, B. y DEL CERRO, R.A. (2015). ¿Cómo valoran los diputados su presencia en las redes sociales?: Análisis de la utilización de Internet en el Congreso de los Diputados durante la X Legislatura. Doxa Comunicación, 21, 161-183.

BALCELLS, J. y CARDENAL, A.S. (2013). Internet y competición electoral: el caso de Esquerra Republicana de Catalunya. Revista Española de Investigaciones Sociológicas, 141, 3-28. doi: http://dx.doi.org/10.5477/cis/reis.141.3

BIMBER, B. (1998). The Internet and political transformation: Populism, community, and accelerated pluralism. Polity, 31(1), 133-160. doi: http://dx.doi. org $/ 10.2307 / 3235370$

CAMPOS, E. (2011). El desarrollo de la ciberdemocracia en el Congreso de los Diputados: La comunicación e interacción entre ciudadanos y parlamentarios a través de internet (2004-2008). Tesis doctoral. Universidad Complutense, Madrid. Recuperado de http://eprints.ucm.es/12401/1/T31297.pdf 
CEBRIÁN, E., VÁZQUEZ, T., y OLABARRIETA, A. (2013). ¿Participación y democracia en los medios sociales?: El caso de Twitter en las elecciones vascas de 2012. adComunica, 6, 39-63.

DADER, J.L. (2003). Ciberdemocracia y comunicación política virtual: el futuro de la ciudadanía electrónica tras la era de la televisión. En S. BERROCAL. (coord.), Comunicación política en televisión y nuevos medios (pp. 309-342). Barcelona: Ariel Comunicación.

DADER, J.L., CHENG, L., CAMPOS, E., QUINTANA, N., y VIZCAÍNO-LAORGA, R. (2014). Las webs de los partidos españoles en campaña electoral. Continuismo entre 2008 y 2011. Trípodos, 34, 115-152.

DAHLGREN, P. (2012): Mejorar la participación: la democracia y el cambiante entorno de la web. En D. INNERARITY y S. CHAMPAGNE (eds.), Internet y el futuro de la democracia (pp. 45-67). Barcelona: Paidós.

DAPENA, B. y RÚAS ARAUJO, J. (2011). Los diputados del Parlamento Gallego en Facebook. Redmarka, 7, 77-106.

Dertouzos, M.L. (1997): Qué será: Cómo cambiará nuestras vidas el nuevo mundo de la informática. Barcelona: Planeta.

FAGÉS-RAMIÓ, R. (2008). Actitud 2.0: la política más allá de los blogs. IDP. Revista de Internet, Derecho y Política, 7, 19-25. Recuperado de http://www.uoc. edu/idp/7/dt/esp/fages.pdf

FERBER, P., FOLTZ, F. y PUGLIESE, R. (2007). Cyberdemocracy and online politics: A new model of interactivity. Bulletin of Science, Technology \& Society, 27(5), 391-400. doi: http://dx.doi.org/10.1177/0270467607304559

GROSSMAN, L. (1995). The electronic republic: Reshaping American democracy in the information age. New York: Penguin Books.

HARFOUSH, R. (2010). Yes we did. Cómo construimos la marca Obama a través de las redes sociales. Barcelona: Gestión 2000.

Intelligence Compass (2010). Informe sobre política y Redes Sociales. Recuperado de http://intelligencecompass.blogspot.com.es/2010/10/politicos-y-redes-sociales-informe.html

IZQUIERDO, L. (2012). Las redes sociales en la política española: Twitter en las elecciones de 2011. Estudos em Comunicação, 11, 139-153.

KALMAN, Y.M. y RAFAELI, S. (2005): Email chronemics: Unobtrosive profiling of response times. Proceedings of te 38th Hawaii International Conference on System Sciencies. doi: http://dx.doi.org/10.1109/hicss.2005.231

LILLEKER, D.G. y JACKSON, N.A. (2008). Politicians and Web 2.0: the current bandwagon or changing the mindset? Paper presented at the Politics: Web 2.0 International Conference. April 17-18, 2008. London: Royal Holloway, University of London. Recuperado de http://www.newpolcom.rhul.ac.uk/politics-web-20-paper-download/Lilleker\%20\%20Jackson\%20Web\%202\%200\%20 2008.pdf

LILLEKER,D.G.y JACKSON,N.A.(2009).Going beyond informing?Onlineinteraction and the UK EP candidates. Recuperado de http://www.academia.edu/588817/ Going_beyond_informing_Online_interaction_and_the_UK_EP_candidates

MANCERA, A. y PANO, A. (2013). El discurso político en Twitter: análisis de mensajes que "trinan". Barcelona: Antrophos. 
MARGOLIS, M., y RESNICK, D. (2000). Politics as Usual: The Cyberspace Revolution. Thousand Oaks, CA: Sage.

MCMILLAN, S.J. (2002). A four-part model of cyber-interactivity. New Media \& Society, 4(2), 271-291. doi: http://dx.doi.org/10.1177/14614440222226370

NEGROPONTE, N. (1995). El mundo digital. Barcelona: Ediciones B.

NORRIS, P. (2003). Preaching to the converted? Pluralism, participation and party websites. Party Politics, 9 (1), 21-45. doi: http://dx.doi.org/10.2139/ssrn.297160

PAPACHARISI, Z. (2009). The citizen is the message. Alternative modes of civic engagement. En Z. PAPACHARISI (comp.), Journalism and citizenship: new agendas in communication (pp. 29-43), Londres: Routledge

RHEINGOLD, H. (1993). The Virtual Community: Homesteading on the Electronic Frontier. Reading: MA. Addison-Wesley.

RUBIO, R. (2009). Quiero ser como Obama (me pido una red social). Cuadernos de pensamiento político, 21, 123-154.

TREJO, R. (2011). ¿Hacia una política 2.0? Potencialidades y límites de la red de redes. Nueva Sociedad, 235, 62-73.

TÚÑEZ, M. y SIXTO, J. (2011). Redes sociales, política y Compromiso 2.0: La comunicación de los diputados españoles en Facebook. Revista Latina de Comunicación Social, 66, 1- 25. doi: http://dx .doi.org/10.4185/rlcs-66-2011-930-216-246

VALERA, L., GAMIR, J., y LÓPEZ, G. (2015). La blogosfera política española en las Elecciones Generales 2011. Una comparación entre blogs de candidatos, periodistas y ciudadanos. Doxa Comunicación, 21, 79-111.

VELA DELFA, C. (2005). El correo electrónico: El nacimiento de un nuevo género. Tesis Doctoral. Universidad Complutense, Madrid. Recuperado de http://biblioteca.ucm.es/tesis/fll/ucm-t29391.pdf

YUS RAMOS, F. (2010). Ciberpragmática 2.0. El uso del lenguaje en internet. Barcelona: Ariel.

ZURUTUZA, C. (2012). ¿De qué habla Rubalcaba cuando tweetea? La campaña del candidato socialista en Twitter para las elecciones del 20N. I Congreso Internacional en Comunicación Política y Estrategias de Campaña. Comunicación Política 2.p0 y Liderazgo. Recuperado de http://www.alice-comunicacionpolitica. com/files/ponencias/249-F50000aa32491342180003-ponencia-1.pdf 